\title{
Investigating the safety and compliance of using csDMARDs in rheumatoid arthritis treatment through face-to-face interviews: a cross-sectional study in China
}

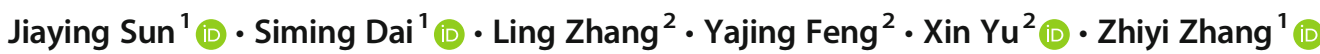

Received: 8 April 2020 / Revised: 6 September 2020 / Accepted: 8 October 2020 / Published online: 15 October 2020

(C) The Author(s) 2020

\begin{abstract}
Rheumatoid arthritis (RA) significantly impacts the health of Chinese patients. Conventional synthetic disease-modifying antirheumatic drugs (csDMARDs) are used as the standard treatment for patients with RA. However, Chinese patients with RA have reported poor compliance with csDMARDs. This study aims to better understand the safety and compliance of using csDMARDs in RA treatment. Face-to-face interviews were conducted by questionnaires on safety and compliance of csDMARDs in 400 patients with RA and 100 rheumatologists from 13 cities in China. Rheumatologists were from Tier 3 Class A hospitals with independent rheumatology departments, who admitted more than 30 patients with RA per week. All patients were diagnosed for $>3$ months before the survey and had been treated with csDMARDs for $>3$ months. The incidence of adverse events (AEs) that attributed to csDMARDs estimated by rheumatologists was lower than that reported by patients for all four prescribed csDMARDs. Also, types of common AEs in rheumatologist's perception differed from those in the patient's report. Only $86 \%(116 / 135)$ of patients claimed they notified their rheumatologist about AEs, and 40.8\% (150/368) of patients did not strictly adhere to their prescribed treatment. Reasons why patients were not compliant with their treatment, other than AEs, included symptoms being less severe, travel, and busy working life/business trips. This study revealed gaps in perceptions of csDMARDs-related AEs and medication adherence between rheumatologists and patients. These findings suggested adequate doctor-patient communications, and considerations of multiple real-world situations may improve adherence in the treatment of RA patients.
\end{abstract}

\section{Key Points}

- This study identified gaps in rheumatologists' perception of the prevalence and type of AEs experienced by their patients, which could potentially help them improve their patients' compliance with treatment.

Keywords Adverse events $\cdot$ Compliance $\cdot \operatorname{csDMARD} \cdot$ Methotrexate $\cdot$ Questionnaire $\cdot$ Rheumatoid arthritis

\section{Introduction}

Rheumatoid arthritis (RA) is a chronic autoimmune condition associated with gradual damage and disability of joints [1].

Electronic supplementary material The online version of this article (https://doi.org/10.1007/s10067-020-05458-w) contains supplementary material, which is available to authorized users.

Zhiyi Zhang

zhangzhiyi2014@163.com

1 Department of Rheumatology and Immunology, First Affiliated Hospital of Harbin Medical University,

Harbin 150086, Heilongjiang, China

2 Shanghai Roche Pharmaceuticals Ltd., Shanghai 201203, China
RA affects $0.24 \%$ of the global population and $0.3-1 \%$ of the population in developed countries [2, 3]. In China, the prevalence of RA is $0.2-0.37 \%$, with a female to male patient ratio of $6: 1[4,5]$.

The standard clinical treatment for patients with RA is the administration of disease-modifying antirheumatic drugs (DMARDs) [6]. These in turn can be classified into conventional synthetic DMARDs (csDMARDs), biological DMARDs (bDMARDs), and targeted synthetic DMARDs (tsDMARDs) [7]. csDMARDs include methotrexate (MTX), leflunomide (LEF), and sulfasalazine (SASP; also known as salazosulfapyridine); bDMARDs consist of inhibitors targeting $\mathrm{T}$ cells (abatacept), B cells (rituximab), interleukin6 (IL-6; tocilizumab), and tumor necrosis factor (e.g., 
adalimumab and etanercept); and tsDMARDs include the Janus kinase inhibitors, tofacitinib, and baricitinib [7].

MTX is recommended by the 2019 European League Against Rheumatism (EULAR) guidelines as first-line treatment for RA, as monotherapy, and in combination with other drugs [7]. MTX is the anchor drug for RA treatment because of its efficacy, safety profile, flexible administration (the mode of administration and dose can be individualized), and low cost (compared with other DMARDs), as well as the extensive clinical experience and familiarity with this drug among rheumatologists [7, 8]. Studies have shown that MTX reduces comorbidities and mortality in RA [9, 10]. LEF or SASP should be considered for first-line treatment in cases where patients are contraindicated or have early intolerance to MTX [7]. In addition, EULAR guidelines recommend bDMARDs and tsDMARDs to be used in combination with a csDMARD. IL-6 pathway inhibitors and tsDMARDs may have some advantages (e.g., efficacy and alternative modes of administration) over other bDMARDs in patients who are unable to use csDMARDs as co-medication [7, 11, 12].

The treat-to-target recommendations for RA not only aim for remission or low disease activity but also for optimizing the patient's quality of life [13]. The 2019 EULAR guidelines recommend monitoring active RA every $1-3$ months using a composite assessment of disease activity that comprises joint counts and American College of Rheumatology (ACR)EULAR definitions for the remission [7, 8, 14]. EULAR also advocates for the timely adjustment of therapy if there is no improvement in a patient's condition at 3 months or if the target has not been reached at 6 months.

Nonetheless, the full therapeutic effect of medications can only be actualized if patients reasonably comply with the prescribed treatment [15]. It is believed that 33-50\% of all drugs prescribed for chronic conditions are not taken as recommended by physicians [16]. Possible reasons for poor compliance with treatment include side effects related to the treatment and insufficient communication between patients and physicians. A meta-analysis of studies on patients with chronic conditions reported that many patients had significant doubts, unanswered questions, and apprehension about their treatment plans, indicating a patient-physician disconnect in terms of their respective views on the need for treatment [17]. Compliance rates (defined as $>80 \%$ compliance with the prescribed treatment) for patients with RA in China ranged from 38.6 to $80.2 \%$ in two studies $[18,19]$. In another Chinese study, patient-reported csDMARDs adherence (also defined as $>80 \%$ compliance with the prescribed treatment) was $38 \%$ [20]. Common side effects of csDMARDs are nausea, diarrhea, alopecia, and rash [21]. The side effects of MTX, which also include post-treatment fatigue, headaches, and rheumatoid nodule formation, can be reduced with folic acid supplementation [22]. It is believed that if common side effects are not monitored, patients may either stop medication without consulting their physicians or start taking alternative medicines [23]. However, there is a limited understanding of rheumatologists' perceptions of adverse events (AEs) from csDMARD use in China.

In this study, we conducted interviews across China with rheumatologists, as well as patients with RA. We first investigated their respective perceptions of AEs arising from csDMARD use, and then explored the reasons for poor patient compliance to csDMARDs. Results from this study will be helpful for rheumatologists to improve their patients' compliance with RA treatment.

\section{Materials and methods}

Between 14 November and 11 December 2018, face-to-face interviews were conducted with 400 patients with RA, as well as 100 rheumatologists from 13 cities in China: Beijing, Shanghai, Guangzhou, Hangzhou, Chengdu, Fuzhou, Shenyang, Wuhan, Xi'an, Nanjing, Jinan, Zhengzhou, and Changsha, which covered both first-tier and second-tier cities. Rheumatologists were from Tier 3 Class A hospitals with independent rheumatology departments, and there were at most two rheumatologists from the same hospital. The inclusion criteria for rheumatologists were as follows: had $\geq 5$ years' experience as attending physicians, deputy chief physicians or chief physicians, have attended to $>30$ patients with RA per week, and routinely made decisions about the course of treatment for patients with RA. All patients were aged $\geq 18$ years, diagnosed with RA for $>3$ months prior to the survey, and had been treated with csDMARDs for $>3$ months. Patients who had stopped csDMARD therapy for $<3$ months were still eligible to participate in the survey. The ratio of physicians and patients was controlled at 1:4 in the same hospital. Informed consent was obtained from all study participants at the enrollment.

The face-to-face interviews with both patients and rheumatologists were facilitated via patient- or rheumatologistspecific questionnaires. In the patient questionnaire (Online Resource 1), each patient was asked whether he/she (a) had experienced any AEs while receiving treatment for RA and to select the $\mathrm{AE}(\mathrm{s})$ from a list, and (b) had taken csDMARDs in strict accordance with the doctor's advice and to indicate any reasons for non-compliance. The questionnaire for rheumatologists (Online Resource 2) asked each physician to estimate, based on individuals clinical experience, the following parameters for patients with RA who received csDMARDs: (a) incidence of AEs, (b) circumstances under which rheumatologists considered AEs as serious, (c) the proportion of patients who would not comply with treatment plans, and (d) the ideal versus actual average dosage of MTX and LEF prescribed to Chinese patients with RA. 
Patient-reported and rheumatologist-estimated data were analyzed using SAS Studio 3.7 (SAS Institute, Inc., Cary, NC, USA). All analyses were descriptive.

\section{Results}

\section{Participant characteristics}

The ratio of female to male patients who participated in this study was $2: 1$. MTX was the most commonly prescribed csDMARD, followed by LEF ( $50.5 \%$ and $43.0 \%$, respectively). The most prevalent comorbidities were hypertension $(42.3 \%)$, diabetes $(18.3 \%)$, and hyperlipidemia (14.3\%).

Per the estimate of rheumatologists, a median of 40 outpatients was seen per week with $20 \%$ (median) of patients were newly diagnosed with RA. The most prescribed regimen for newly diagnosed patients with RA was one csDMARD plus nonsteroidal anti-inflammatory drugs $(25.0 \%)$, followed by a combination of two csDMARDs $(22.5 \%)$. The characteristics of rheumatologists and patients in the study are shown in Table 1.

\section{AEs from csDMARDs}

Rheumatologist-estimated median AE rates were $15 \%$ for patients receiving MTX and LEF, and 10\% for patients using SASP and hydroxychloroquine (HCQ; Table 2). On the other hand, the proportion of patients who reported experiencing AEs after treatment with MTX, LEF, SASP, and HCQ was $39.6 \%, 33.7 \%, 48.6 \%$, and $14.6 \%$, respectively.

As for common AEs, rheumatologists were asked either the csDMARDs-related symptoms/results were common or not, and the results of patients reported experiencing each AE were analyzed (Table 3). Similarly, nausea/vomiting, acidity/ bloating and distention/loose motions, and hair loss/rash ranked the front for both rheumatologists and patients. High proportions of rheumatologists identified laboratory/imaging results including leukopenia, neutropenia, thrombocytopenia, interstitial lung disease, and liver/kidney function impairment as common AEs, while the occurrence of those AEs reported by patients was lower than expected. For MTX, canker sores were estimated as common by $51 \%$ of rheumatologists, which was higher than other csDMARDs and differed with results reported by patients.

The circumstances under which rheumatologists considered an AE to be serious are presented in Fig. 1. Results indicate that rheumatologists have a higher tendency to consider AEs classified as laboratory/imaging results as serious, compared with other AEs. AEs categorized as laboratory/ imaging results were associated with the highest total proportion of rheumatologists who classified them as serious AEs regardless of severity (i.e., upon occurrence), when mild (i.e., patient passively confirms the occurrence of tolerable AE), or when moderate (i.e., patient actively confirms the occurrence of tolerable $\mathrm{AE}$ and requests adjustment of treatment).

\section{Non-compliance with csDMARDs}

Among 100 participating rheumatologists, the estimated mean proportion of patients who may refuse treatment with csDMARD(s) and stop or reduce the dosage of csDMARD(s) without prior consultation to be $6.7 \%$ and $12.3 \%$, respectively. However, from 368 patients who answered the question about medication adherence, the proportions of patients that reported not strictly adhere to prescription varied from 34.5 to $54.3 \%$ among four csDMARDs (Table 4). Overall, $40.8 \%$ (150/368) of patients reported that they did not strictly adhere to their prescribed treatment; $37.5 \%(138 / 368)$ of patients reported that they occasionally missed a dose, $3.3 \%$ (12/368) reported frequently missing a dose, and 1.6\% (6/368) of patients reduced the dose without consulting their rheumatologist (six patients chose two answers at the same time).

For patients who reported not taking csDMARDs regularly, reduction in the severity of symptoms was the most common reason provided by patients $(60.7 \%, 91 / 150)$. The next most common reasons given were travel and being busy with work/business trips $(41.3 \%, 62 / 150 ; 36.7 \%, 55 / 150)$. Additionally, $30.7 \%$ (46/150) of patients who did not comply with their therapy attributed non-compliance to pre-existing AEs from treatment with csDMARD(s). Also, 28\% (42/150) of patients reported non-compliance because of concerns about potential long-term AEs (Fig. 2).

\section{Rheumatologist-estimated ideal and actual dose of MTX and LEF}

Of the rheumatologists interviewed, 54\% (54/100) considered MTX $10.0 \mathrm{mg}$ weekly to be the minimum dose needed to achieve efficacy (ideal dose), and 73\% (73/100) considered this dose to be the most frequently prescribed MTX dose (actual dose). For LEF, 65.7\% (65/99) of the rheumatologists reported $20.0 \mathrm{mg}$ daily as the ideal dose, and $64.7 \%(64 / 99)$ reported this as the actual dose prescribed (Fig. 3).

\section{Discussion}

RA is a significant health and economic burden in China. csDMARDs are the most widely used first-line treatment because of their affordability, efficacy, and safety [8, 24, 25]. However, compliance rates with csDMARDs (38\%) in China are far from ideal [20]. In this study, we revealed gaps in perceptions of AEs and adherence related to csDMARDs between rheumatologists and their patients. Rheumatologistestimated AE rates and types of common AEs were different 
Table 1 Participant characteristics

\begin{tabular}{ll}
\hline & Participants \\
\hline Patient characteristics & $N=400$ \\
Sex (female), $n$ (\%) & $269(67.3)$ \\
Age (years), mean (SD) & $56.1(10.9)$ \\
BMI (kg/m $)^{2}$, mean (SD) & $23.2(3.2)$ \\
Prescribed csDMARDs, $n(\%)^{\mathrm{a}}$ & \\
MTX & $202(50.5)$ \\
LEF & $172(43.0)$ \\
SASP & $35(8.8)$ \\
HCQ & $55(13.8)$ \\
Comorbidities present, $n(\%)$ & \\
Hypertension & $169(42.3)$ \\
Diabetes & $73(18.3)$ \\
Hyperlipidemia & $57(14.3)$ \\
Coronary heart disease & $43(10.8)$ \\
Respiratory diseases & $37(9.3)$ \\
Chronic renal disease & $14(3.5)$ \\
Chronic liver disease & $10(2.5)$ \\
Stroke & $7(1.8)$ \\
Osteoporosis & $4(1.0)$ \\
Tumor(s) & $4(1.0)$ \\
Anemia & $1(0.3)$ \\
Other rheumatic diseases & $23(5.8)$ \\
Daily drug treatment & \\
Types of drugs, median (IQR) & $3.0(3.0)$ \\
Number of tablets taken, median (IQR) & \\
Rheumatologist characteristics & $6.0(6.0)$ \\
Rheumatologist seniority, $n(\%)$ & $N=100$ \\
Attending physician & \\
Deputy chief physician & $39(39.0)$ \\
Chief physician & $25.0(22.5)$ \\
Patients seen, median (IQR) & $22.5(30.0)$ \\
Outpatients per week & $15.0(20.0)$ \\
Inpatients per month & $10.0(10.0)$ \\
Rheumatologist-estimated patient characteristics (\% of patients & $5.0(9.0)$ \\
median (IQR) & $20(20.0)$ \\
Newly diagnosed outpatients & \\
Follow-up patients among outpatients & $20.0(15.0)$ \\
Received drug therapy for RA among newly diagnosed & $80.0(15.0)$ \\
outpatients & $98.0(10.0)$ \\
Prescribed regimen for newly diagnosed RA patients & \\
One csDMARD + NSAIDs & \\
Combination of two csDMARDs & \\
csDMARD alone & \\
One csDMARD + glucocorticoid & \\
bDMARD/tsDMARD alone & \\
\hline
\end{tabular}

DDMARD biologic disease-modifying antirheumatic drug, BMI body mass index, $\operatorname{cs} D M A R D$ conventional synthetic disease-modifying antirheumatic drug, $H C Q$ hydroxychloroquine, $I Q R$ interquartile range, $L E F$ leflunomide, MTX methotrexate, NSAIDs nonsteroidal antiinflammatory drugs, $R A$ rheumatoid arthritis, $S A S P$ salazosulfapyridine, $S D$ standard deviation, tsDMARD targeted synthetic disease-modifying antirheumatic drug

${ }^{\text {a }}$ Sum of $n$ does not add up to 400 because patients may be prescribed two csDMARDs

${ }^{\mathrm{b}}$ Includes medication for RA and comorbidities

from those reported by patients for all four csDMARDs. More patients reported they did not strictly adhere to their prescribed treatment than estimates of rheumatologists. We also showed that, in addition to AEs and concerns of long-term AEs,
Table 2 AEs from csDMARD use

\begin{tabular}{lc}
\hline & Participants \\
\hline Rheumatologist-estimated & $N=100$ \\
AE rate in patients using various csDMARDs $(\%)$, median (IQR) \\
MTX & $15.0(20.0)$ \\
LEF & $15.0(10.0)$ \\
SASP & $10.0(10.0)$ \\
HCQ & $10.0(5.0)$ \\
Patient-reported & $N=400$ \\
Experienced AEs after taking prescribed csDMARD, & $n(\%)$ \\
MTX $(n=202)$ & $80(39.6)$ \\
LEF $(n=172)$ & $58(33.7)$ \\
SASP $(n=35)$ & $17(48.6)$ \\
HCQ $(n=55)$ & $8(14.6)$ \\
Changed csDMARD, $n(\%)$ & $113(28.3)$ \\
Notified rheumatologist about AEs, $n(\%)^{\mathrm{a}}$ & $116(85.9)$
\end{tabular}

$A E$ adverse event, $c S D M A R D$ conventional synthetic disease-modifying antirheumatic drug, $H C Q$ hydroxychloroquine, $I Q R$ interquartile range, $L E F$ leflunomide, $M T X$ methotrexate, $S A S P$ salazosulfapyridine

${ }^{\mathrm{a}} n=135$

reduction in the severity of symptoms, traveling, and a busy working life/business trips are reasons why patients may not be compliant with their treatment.

The AEs for each of the four csDMARDs identified by rheumatologists differed from patient reports, suggesting that there are gaps in rheumatologists' understanding of the occurrence and types of AEs reported by their patients. In our study, more rheumatologists but not patients regarded laboratory/imaging results, including leukopenia, neutropenia, thrombocytopenia, interstitial lung disease, and liver/kidney function impairment, as common AEs. Although, the patient-reported AEs were not evaluated by physicians and some of the AEs may not be led by csDMARDs, a possible reason for this difference in perception could be due to the communication gap. Only $86 \%(116 / 135)$ of patients reported that they had notified their rheumatologist about AEs. Lack of communication could lead to misestimating AE prevalence and severity among rheumatologists. In a recent global survey, $61 \%$ of patients with RA reported feeling uncomfortable about raising fears or concerns with their physicians, while $68 \%$ of physicians wished they and their patients communicated more about their RA goals and treatment [26]. Some of these patients $(31 \%)$ were uncomfortable in communicating openly with physicians because of concerns that the physicians would view them as being difficult, which could influence their subsequent quality of care. Also, $14 \%$ of patients felt that they lacked knowledge 
Table 3 Common AEs estimated by rheumatologists and AEs reported by patients for MTX, LEF, SASP, and HCQ

\begin{tabular}{|c|c|c|c|c|c|c|c|c|}
\hline & \multicolumn{2}{|l|}{ MTX } & \multicolumn{2}{|l|}{ LEF } & \multicolumn{2}{|l|}{ SASP } & \multicolumn{2}{|l|}{ HCQ } \\
\hline & $\begin{array}{l}\text { Rheumatologist- } \\
\text { estimated }^{\text {a }} \\
N=100\end{array}$ & $\begin{array}{l}\text { Patient- } \\
\text { reported }^{\mathrm{b}} \\
n=80\end{array}$ & $\begin{array}{l}\text { Rheumatologist- } \\
\text { estimated }^{\text {a }} \\
N=100\end{array}$ & $\begin{array}{l}\text { Patient- } \\
\text { reported }^{\mathrm{b}} \\
n=58\end{array}$ & $\begin{array}{l}\text { Rheumatologist- } \\
\text { estimated }^{\text {a }} \\
n=96\end{array}$ & $\begin{array}{l}\text { Patient- } \\
\text { reported }^{b} \\
n=17\end{array}$ & $\begin{array}{l}\text { Rheumatologist- } \\
\text { estimated }^{\text {a }} \\
n=95\end{array}$ & $\begin{array}{l}\text { Patient- } \\
\text { reported }^{\mathrm{b}} n \\
=8\end{array}$ \\
\hline \multicolumn{9}{|c|}{ Gastrointestinal symptoms, $n(\%)$} \\
\hline Abdominal pain & $29(29.0)$ & $12(15.0)$ & $32(32.0)$ & $7(12.1)$ & $32(33.3)$ & 0 & $28(29.5)$ & 0 \\
\hline Diarrhea & $30(30.0)$ & $13(16.3)$ & $34(34.0)$ & $12(20.7)$ & $20(20.8)$ & $1(5.9)$ & $14(14.7)$ & 0 \\
\hline Constipation & $9(9.0)$ & $9(11.3)$ & $19(19.0)$ & $9(15.5)$ & $12(12.5)$ & $2(11.8)$ & $6(6.3)$ & $1(12.5)$ \\
\hline Nausea/vomiting & $81(81.0)$ & $46(57.5)$ & $53(53.0)$ & $19(32.8)$ & $57(59.4)$ & $5(29.4)$ & $22(23.2)$ & $3(37.5)$ \\
\hline Canker sores & $51(51.0)$ & $14(17.5)$ & $16(16.0)$ & $10(17.2)$ & $15(15.6)$ & $2(11.8)$ & $6(6.3)$ & $1(12.5)$ \\
\hline $\begin{array}{l}\text { Acidity/bloating and } \\
\text { distention/loose mo- } \\
\text { tions }\end{array}$ & $37(37.0)$ & $34(42.5)$ & $37(37.0)$ & $25(43.1)$ & $26(27.1)$ & $6(35.3)$ & $19(20.0)$ & $3(37.5)$ \\
\hline \multicolumn{9}{|l|}{ Behavioral symptoms, $n(\%)$} \\
\hline Insomnia & $21(21.0)$ & $16(20.0)$ & $15(15.0)$ & $11(19.0)$ & $12(12.5)$ & $2(11.8)$ & $22(23.2)$ & $1(12.5)$ \\
\hline $\begin{array}{l}\text { Aversion to drug name, } \\
\text { sight, and thought }\end{array}$ & $7(7.0)$ & $2(2.5)$ & $2(2.0)$ & $1(1.7)$ & $8(8.3)$ & 0 & $7(7.4)$ & $1(12.5)$ \\
\hline $\begin{array}{l}\text { Memory loss/difficulty } \\
\text { concentrating }\end{array}$ & $2(2.0)$ & $5(6.3)$ & $7(7.0)$ & $2(3.5)$ & $12(12.5)$ & $1(5.9)$ & $10(10.5)$ & 0 \\
\hline Anxiety/depression & $10(10.0)$ & $6(7.5)$ & $11(11.0)$ & $6(10.3)$ & $17(17.7)$ & 0 & $10(10.5)$ & 0 \\
\hline \multicolumn{9}{|c|}{ Non-specific symptoms, $n(\%)$} \\
\hline Weakness/fatigue & $28(28.0)$ & $16(20.0)$ & $27(27.0)$ & $16(27.6)$ & $23(24.0)$ & $7(41.2)$ & $19(20.0)$ & $1(12.5)$ \\
\hline Hair loss/rash & $40(40.0)$ & $21(26.3)$ & $47(47.0)$ & $12(20.7)$ & $29(30.2)$ & $6(35.3)$ & $35(36.8)$ & $2(25.0)$ \\
\hline $\begin{array}{l}\text { Burning in the } \\
\text { chest/whole body feel- } \\
\text { ing hot }\end{array}$ & $9(9.0)$ & $2(2.5)$ & $7(7.0)$ & 0 & $10(10.4)$ & $1(5.9)$ & $12(12.6)$ & 0 \\
\hline \multicolumn{9}{|c|}{ Laboratory/imaging results, n (\%) } \\
\hline Leukopenia & $61(61.0)$ & $5(6.3)$ & $50(50.0)$ & $3(5.2)$ & $31(32.3)$ & $1(5.9)$ & $17(17.9)$ & 0 \\
\hline Neutropenia & $33(33.0)$ & $2(2.5)$ & $20(20.0)$ & $3(5.2)$ & $24(25.0)$ & $1(5.9)$ & $7(7.4)$ & 0 \\
\hline Thrombocytopenia & $23(23.0)$ & 0 & $22(22.0)$ & $2(3.5)$ & $20(20.8)$ & $2(11.8)$ & $10(10.5)$ & 0 \\
\hline Interstitial lung disease & $35(35.0)$ & $9(11.3)$ & $11(11.0)$ & $2(3.5)$ & $8(8.3)$ & 0 & $5(5.3)$ & 0 \\
\hline $\begin{array}{l}\text { Liver/kidney function } \\
\text { impairment }\end{array}$ & $46(46.0)$ & $13(16.3)$ & $52(52.0)$ & $9(15.5)$ & $35(36.5)$ & $3(17.7)$ & $19(20.0)$ & $1(12.5)$ \\
\hline
\end{tabular}

$A E$ adverse event, $c S D M A R D$ conventional synthetic disease-modifying antirheumatic drugs, $H C Q$ hydroxychloroquine, $L E F$ leflunomide, $M T X$ methotrexate, SASP salazosulfapyridine

${ }^{a}$ Rheumatologists were asked to estimate whether each $\mathrm{AE}$ was common, and calculated the number and proportion of people who believed it was a common AE

${ }^{\mathrm{b}}$ Patients were asked to report the AEs they once experienced and calculated the number and proportion of each $\mathrm{AE}$

or understanding of RA management. A pilot educational intervention study conducted in China revealed that the educational program on RA management not only significantly improved patients' knowledge but also their confidence in managing their disease effectively [27]. Though many reasons contribute to the differences in perceptions of AEs, our study suggests that it is important to optimize communication between patients and their rheumatologists to improve $\mathrm{AE}$ recognition and reporting, and the management of RA.

Nonetheless, AEs associated with MTX use reported in this study were similar to the expected AE profile for MTX [28].
Most of the patient-reported AEs were gastrointestinal symptoms, which is consistent with a survey conducted in Australia [29]. Compared with Australian patients with RA, the prevalence rates of patient-reported nausea and skin rash were similar (23\% vs $\sim 28 \%$, and $10 \%$ versus $\sim 12 \%$, respectively). The proportion of Australian patients who reported mouth ulcers $(\sim 25 \%)$, diarrhea $(\sim 20 \%)$, and stomach pain $(\sim 15 \%)$ was higher than that reported in our study $(7 \%, 6.5 \%$, and $6 \%$, respectively). On the other hand, more patients in our study experienced vomiting than in the Australian study (23\% vs $7 \%$ ). The AEs reported for LEF and SASP were also consistent with those reported in other multinational studies [30,31]. 
Fig. 1 Circumstances under which the rheumatologists considered the AEs as serious ( $N$ $=100)$. AE, adverse event. ${ }^{\text {a }}$ Patient passively confirms the occurrence of tolerable AE. ${ }^{\mathrm{b}}$ Patient actively confirms the occurrence of tolerable $\mathrm{AE}$ and requests adjustment of treatment. ${ }^{c}$ Patient actively confirms the occurrence of intolerable $\mathrm{AE}$ and strongly requests intervention or adjustment of treatment. ${ }^{\mathrm{d}}$ Mild was defined as $3.0 \times 10^{9} / \mathrm{L}$, moderate as $2.0 \times 10^{9} / \mathrm{L}$, and severe as $1.0 \times 10^{9} / \mathrm{L}$. ${ }^{e}$ Mild was defined as $1-3 \times$ normal value, and moderate as $>3 \times$ normal value. Severe was not defined in the questionnaire for rheumatologists, hence not included as an option. ${ }^{\mathrm{f}}$ Mild was defined as 100 $\times 10^{9} / \mathrm{L}$, moderate as $50 \times 10^{9} / \mathrm{L}$, and severe as $25 \times 10^{9} / \mathrm{L} .{ }^{\mathrm{g}}$ Mild was defined as $2.0 \times 10^{9} / \mathrm{L}$, moderate as $1.0 \times 10^{9} / \mathrm{L}$, and severe was defined as $0.5 \times 10^{9} / \mathrm{L}$

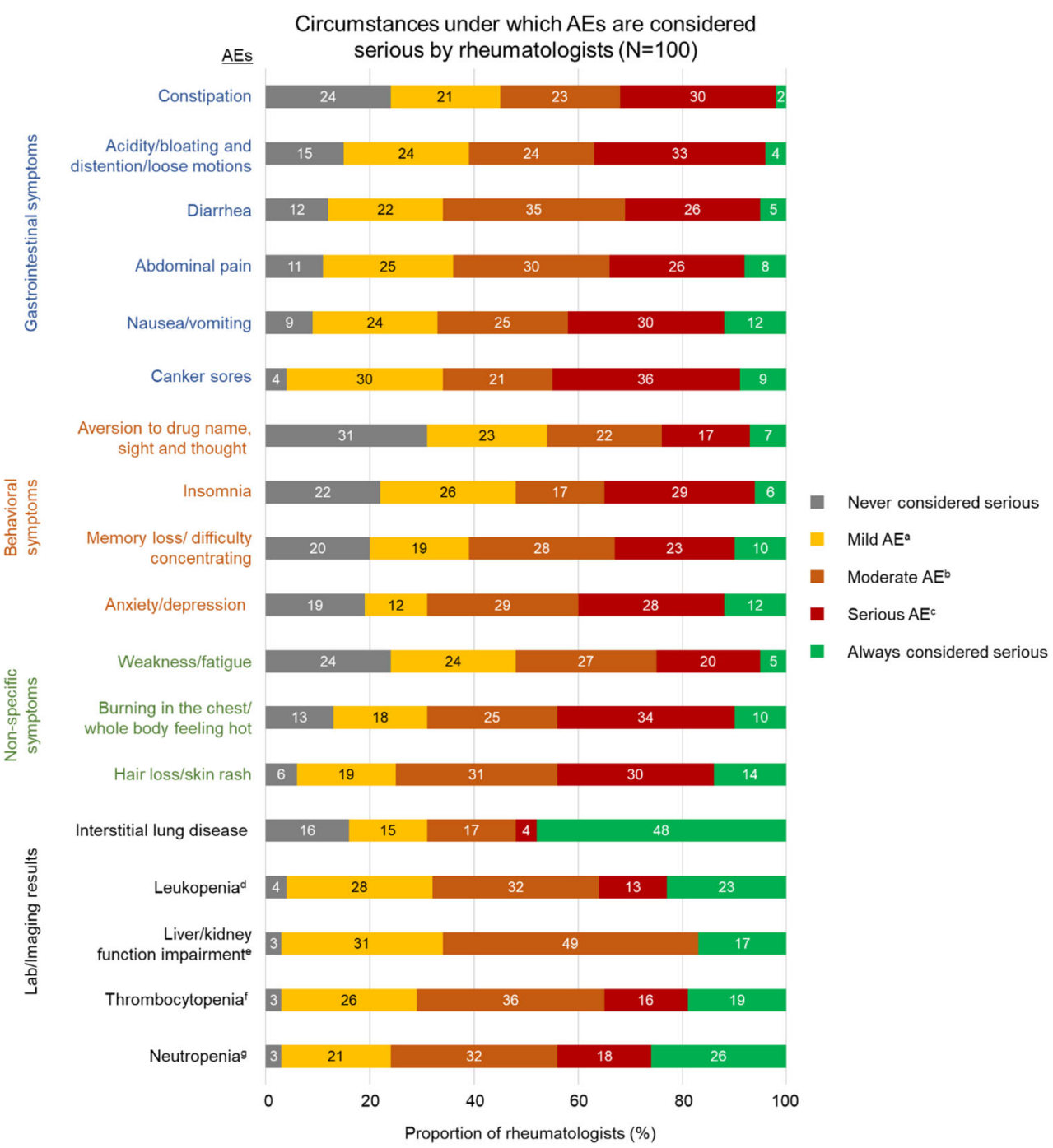

However, due to the paucity in the literature of similarly designed studies, AE occurrence cannot be directly compared.

The non-compliance rate $(40.8 \%)$ was within the range of those reported by other RA studies conducted in China (19.8$61.4 \%$ ) [18, 19]. Non-compliance would eventually worsen disease activity, which acts against the treat-to-target strategy. Monitoring and detecting the common side effects at the early stage are essential in managing patients [23]. In this study,
csDMARD treatment-related AEs were the cause of noncompliance for $30.7 \%$ of patients, and $28.0 \%$ of patients were non-compliant because they were concerned about potential long-term AEs. However, it is notable that multiple other factors may result in non-compliance, including a reduction in the severity of symptoms, travel, and busy working life/ business trips. In addition, most newly diagnosed patients were prescribed two types of RA drugs (62.5\%), and patients

Table 4 Patient-reported compliance with MTX, LEF, SASP, and HCQ

\begin{tabular}{|c|c|c|c|c|c|}
\hline Drug use adherence, $(\%)$ & $\operatorname{MTX} N=202$ & LEF $N=172$ & $\operatorname{SASP} N=35$ & $\mathrm{HCQ} N=55$ & Total $N=368$ \\
\hline Strictly adhere to doctor's prescription & $119(58.9)$ & $105(61.1)$ & $16(45.7)$ & $36(65.5)$ & $218(59.2)$ \\
\hline Occasionally miss a dose & $74(36.6)$ & $64(37.2)$ & $18(51.4)$ & $19(34.6)$ & $138(37.5)$ \\
\hline Frequently miss a dose & $6(3.0)$ & $6(3.5)$ & $1(2.9)$ & 0 & $12(3.3)$ \\
\hline Reduce the dose without consulting their doctor & $5(2.5)$ & $1(0.6)$ & $2(5.7)$ & $1(1.8)$ & $6(1.6)$ \\
\hline
\end{tabular}

The total proportion exceeded $100 \%$ due to 6 patients selecting 2 answers

$M T X$ methotrexate, $L E F$ leflunomide, SASP salazosulfapyridine, $H C Q$ hydroxychloroquine 


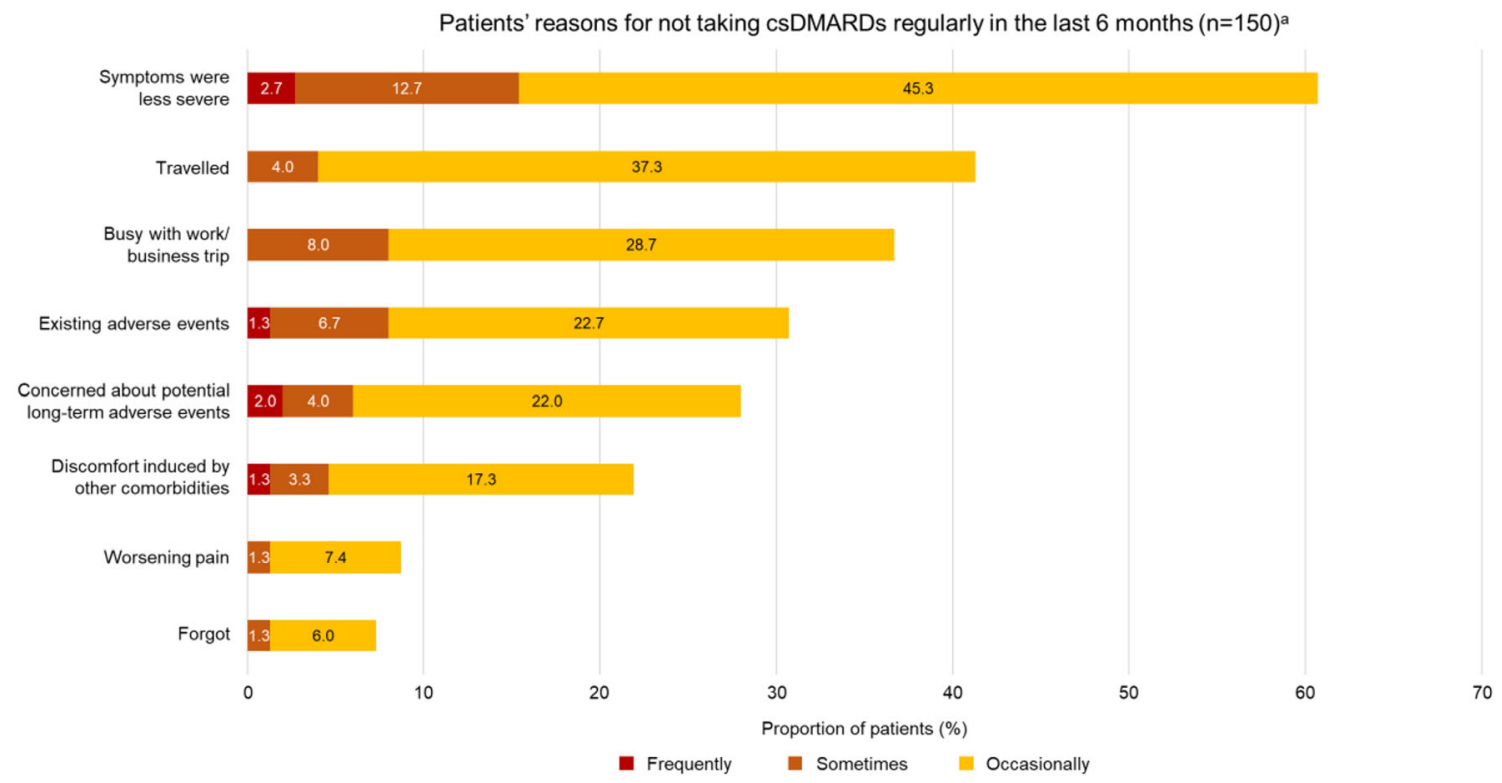

Fig. 2 Patient-reported reasons for not taking csDMARDs regularly within the previous 6 months $(n=150)^{\mathrm{a}}$. AE, adverse event; csDMARD, conventional synthetic disease-modifying antirheumatic

drugs. ${ }^{\text {a}}$ Forty-nine patients reported that they did not take csDMARDs regularly in the previous 6 months because of reasons not specified in the questionnaire (frequently $2.0 \%$; sometimes $10.2 \%$; occasionally $71.4 \%$ )

with RA took a median of three types of drugs and six tablets a day. Patients who took more RA medications had a 1.7-fold higher likelihood of non-compliance with their prescribed treatment [32]. These findings show that AEs and concerns for long-term AEs are important but are not the only reasons why patients may not strictly follow their prescribed treatment. Complex real-world situations should be considered that may lead to non-compliance.

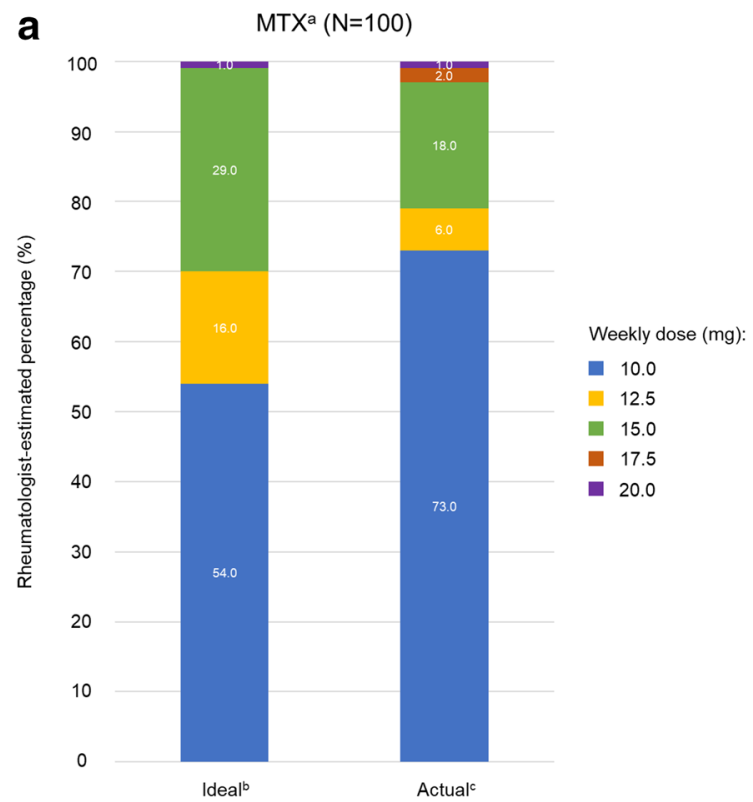

Fig. 3 Rheumatologists' perception of ideal versus actual dose prescribed for a $\operatorname{MTX}(N=100)$ and b LEF $(n=99)$. LEF, leflunomide; MTX,

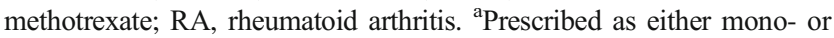
combination therapy in $66.8 \%$ of newly diagnosed patients with RA. 'Ideal dose is defined as the rheumatologists' estimate of the minimum

Rheumatologists' estimation of ideal dosage is the same as the recommended dosage by EULAR for LEF, but not for MTX $[8,33]$. EULAR recommends a rapid escalation of MTX dosage to $20-25 \mathrm{mg} /$ week within 4-6 weeks [7]. However, this recommended dosage does not apply to Asian patients [8]. In China and Japan, the dose of MTX should not exceed $20 \mathrm{mg} /$ week and $16 \mathrm{mg} /$ week, respectively [34, 35]. This difference in dosage between Western and Asian

b

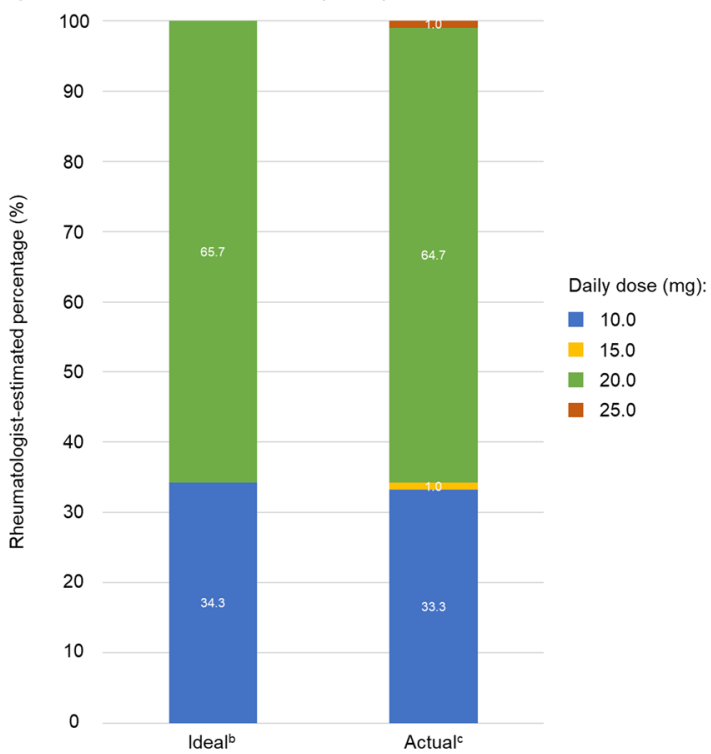

dose required to achieve treatment efficacy. ${ }^{\mathrm{c}}$ Actual dose is defined as the rheumatologists' estimate of the dose that most patients actually take. ${ }^{\mathrm{d}}$ Prescribed as either mono- or combination therapy in $46.9 \%$ of newly diagnosed patients with RA 
populations could possibly be due to the lower body weight and different pharmacogenetic characteristics of the Asian population $[7,36]$. Nonetheless, EULAR guidelines recommend the timely adjustment of therapy if there is no improvement in the patient's condition, or if the treatment target has not been reached [7]. In patients who have failed phase I treatment and present poor prognostic factors, such as failure of $\geq 2$ csDMARDs, a bDMARD or tsDMARD should be added for phase II therapy [7].

The main limitation of this cross-sectional study is that sampling is convenient, not random, which results in selection bias and reduced reliability of the derived conclusions. In this study, the female to male ratio of patients with RA was 2:1, which deviates from the $6: 1$ ratio reported in other studies conducted in China $[18,20]$. Second, the AEs reported by patients were not all evaluated by physicians, which affected the accuracy and may introduce recall bias. Even though AEs that are estimated by rheumatologists and AEs that patients reported in the survey cannot be compared directly, the trends highlighted a gap between the rheumatologists' perception of clinically relevant AEs and the AEs that patients believe to result from csDMARD use. However, there were strengths of this study; our study recruited patients from 13 cities across China and, thus, may provide a more holistic representation of the Chinese patient population $[18,20]$. We conducted questionnaires for both physicians and patients (Online Resource 1 and 2). Surveys investigating intolerance and/or compliance in patients with RA are often focused on patients only [18, 20, 23]. With the additional insights from rheumatologists, this study was able to identify the differences in perceptions of patients versus rheumatologists.

Our results revealed differences in perceptions between patients and rheumatologists in terms of csDMARDs-related AEs and adherence. Patients were less compliant when the severity of RA symptoms was reduced, if they had travel commitments, were busy with work, had pre-existing AEs, and if they had concerns about potential long-term AEs. These findings indicate the importance of adequate doctorpatient communication and consideration of multiple scenarios of non-adherence in the management of RA patients.

Acknowledgments We thank the patients and their families, the investigators, and clinical study sites.

Funding This study is sponsored by Shanghai Roche Pharmaceuticals Ltd. Medical writing support for this manuscript was provided by Bena Lim, Ph.D., of MediTech Media, and funded by Shanghai Roche Pharmaceuticals Ltd.

Availability of data and materials Qualified researchers may request access to individual patient level data through the clinical study data request platform (https://vivli.org/). Further details on Roche's criteria for eligible studies are available here (https://vivli.org/members/ourmembers/). For further details on Roche's Global Policy on the Sharing of Clinical Information and how to request access to related clinical study documents, see here (https://www.roche.com/research_and development/who_we_are_how_we_work/clinical_trials/our_ commitment_to_data_sharing. $\overline{\text { htm }}$ ).

\section{Compliance with ethical standards}

Disclosures Ling Zhang, Yajing Feng, and Xin Yu are employees of Shanghai Roche Pharmaceuticals Ltd. The other authors declare that they have no known conflicts of interest.

Open Access This article is licensed under a Creative Commons Attribution 4.0 International License, which permits use, sharing, adaptation, distribution and reproduction in any medium or format, as long as you give appropriate credit to the original author(s) and the source, provide a link to the Creative Commons licence, and indicate if changes were made. The images or other third party material in this article are included in the article's Creative Commons licence, unless indicated otherwise in a credit line to the material. If material is not included in the article's Creative Commons licence and your intended use is not permitted by statutory regulation or exceeds the permitted use, you will need to obtain permission directly from the copyright holder. To view a copy of this licence, visit http://creativecommons.org/licenses/by/4.0/.

\section{References}

1. An Y, Liu T, He D, Wu L, Li J, Liu Y, Bi L, Zhou B, Lin C, He L, Liu X, Li X, Yang N, Zhang Z, Song H, Wei W, Liu J, Bi Y, Li Z (2017) The usage of biological DMARDs and clinical remission of rheumatoid arthritis in China: a real-world large scale study. Clin Rheumatol 36(1):35-43. https://doi.org/10.1007/s10067-0163424-5

2. Cross M, Smith E, Hoy D, Carmona L, Wolfe F, Vos T, Williams B, Gabriel S, Lassere M, Johns N, Buchbinder R, Woolf A, March L (2014) The global burden of rheumatoid arthritis: estimates from the global burden of disease 2010 study. Ann Rheum Dis 73(7): 1316-1322. https://doi.org/10.1136/annrheumdis-2013-204627

3. Woolf AD, Pfleger B (2003) Burden of major musculoskeletal conditions. Bull World Health Organ 81(9):646-656

4. Zeng QY, Chen R, Darmawan J, Xiao ZY, Chen SB, Wigley R, Le Chen S, Zhang NZ (2008) Rheumatic diseases in China. Arthritis Res Ther 10(1):R17. https://doi.org/10.1186/ar2368

5. Li R, Sun J, Ren LM, Wang HY, Liu WH, Zhang XW, Chen S, Mu R, He J, Zhao Y, Long L, Liu YY, Liu X, Lu XL, Li YH, Wang SY, Pan SS, Li C, Wang HY, Li ZG (2012) Epidemiology of eight common rheumatic diseases in China: a large-scale cross-sectional survey in Beijing. Rheumatology (Oxford) 51(4):721-729. https:// doi.org/10.1093/rheumatology/ker370

6. Smolen JS, Landewe R, Breedveld FC, Buch M, Burmester G, Dougados M, Emery P, Gaujoux-Viala C, Gossec L, Nam J, Ramiro S, Winthrop K, de Wit M, Aletaha D, Betteridge N, Bijlsma JW, Boers M, Buttgereit F, Combe B, Cutolo M, Damjanov N, Hazes JM, Kouloumas M, Kvien TK, Mariette X, Pavelka K, van Riel PL, Rubbert-Roth A, Scholte-Voshaar M, Scott DL, Sokka-Isler T, Wong JB, van der Heijde D (2014) EULAR recommendations for the management of rheumatoid arthritis with synthetic and biological disease-modifying antirheumatic drugs: 2013 update. Ann Rheum Dis 73(3):492-509. https://doi. org/10.1136/annrheumdis-2013-204573

7. Smolen JS, Landewe RBM, Bijlsma JWJ, Burmester GR, Dougados M, Kerschbaumer A, McInnes IB, Sepriano A, van Vollenhoven RF, de Wit M, Aletaha D, Aringer M, Askling J, Balsa A, Boers M, den Broeder AA, Buch MH, Buttgereit F, 
Caporali R, Cardiel MH, De Cock D, Codreanu C, Cutolo M, Edwards CJ, van Eijk-Hustings Y, Emery P, Finckh A, Gossec L, Gottenberg JE, Hetland ML, Huizinga TWJ, Koloumas M, Li Z, Mariette X, Muller-Ladner U, Mysler EF, da Silva JAP, Poor G, Pope JE, Rubbert-Roth A, Ruyssen-Witrand A, Saag KG, Strangfeld A, Takeuchi T, Voshaar M, Westhovens R, van der Heijde D (2020) EULAR recommendations for the management of rheumatoid arthritis with synthetic and biological diseasemodifying antirheumatic drugs: 2019 update. Ann Rheum Dis. https://doi.org/10.1136/annrheumdis-2019-216655

8. Smolen JS, Landewe R, Bijlsma J, Burmester G, Chatzidionysiou K, Dougados M, Nam J, Ramiro S, Voshaar M, van Vollenhoven $\mathrm{R}$, Aletaha D, Aringer M, Boers M, Buckley CD, Buttgereit F, Bykerk V, Cardiel M, Combe B, Cutolo M, van Eijk-Hustings Y, Emery P, Finckh A, Gabay C, Gomez-Reino J, Gossec L, Gottenberg JE, Hazes JMW, Huizinga T, Jani M, Karateev D, Kouloumas M, Kvien T, Li Z, Mariette X, McInnes I, Mysler E, Nash P, Pavelka K, Poor G, Richez C, van Riel P, Rubbert-Roth A, Saag K, da Silva J, Stamm T, Takeuchi T, Westhovens R, de Wit M, van der Heijde D (2017) EULAR recommendations for the management of rheumatoid arthritis with synthetic and biological disease-modifying antirheumatic drugs: 2016 update. Ann Rheum Dis 76(6):960-977. https://doi.org/10.1136/annrheumdis-2016210715

9. Choi HK, Hernán MA, Seeger JD, Robins JM, Wolfe F (2002) Methotrexate and mortality in patients with rheumatoid arthritis: a prospective study. Lancet 359(9313):1173-1177. https://doi.org/ 10.1016/s0140-6736(02)08213-2

10. Wasko MC, Dasgupta A, Hubert H, Fries JF, Ward MM (2013) Propensity-adjusted association of methotrexate with overall survival in rheumatoid arthritis. Arthritis Rheum 65(2):334-342. https://doi.org/10.1002/art.37723

11. Ogata A, Kato Y, Higa S, Yoshizaki K (2019) IL-6 inhibitor for the treatment of rheumatoid arthritis: a comprehensive review. Mod Rheumatol 29(2):258-267. https://doi.org/10.1080/14397595. 2018.1546357

12. Kotyla PJ (2018) Are Janus kinase inhibitors superior over classic biologic agents in RA patients? Biomed Res Int 2018:7492904 7492909. https://doi.org/10.1155/2018/7492904

13. Smolen JS, Aletaha D, Bijlsma JW, Breedveld FC, Boumpas D, Burmester G, Combe B, Cutolo M, de Wit M, Dougados M, Emery P, Gibofsky A, Gomez-Reino JJ, Haraoui B, Kalden J, Keystone EC, Kvien TK, McInnes I, Martin-Mola E, Montecucco C, Schoels M, van der Heijde D, T2T Expert Committee (2010) Treating rheumatoid arthritis to target: recommendations of an international task force. Ann Rheum Dis 69(4):631-637. https://doi.org/10.1136/ard. 2009.123919

14. Felson DT, Smolen JS, Wells G, Zhang B, van Tuyl LH, Funovits J, Aletaha D, Allaart CF, Bathon J, Bombardieri S, Brooks P, Brown A, Matucci-Cerinic M, Choi H, Combe B, de Wit M, Dougados M, Emery P, Furst D, Gomez-Reino J, Hawker G, Keystone E, Khanna D, Kirwan J, Kvien TK, Landewe R, Listing J, Michaud K, MartinMola E, Montie P, Pincus T, Richards P, Siegel JN, Simon LS, Sokka T, Strand V, Tugwell P, Tyndall A, van der Heijde D, Verstappen S, White B, Wolfe F, Zink A, Boers M (2011) American College of Rheumatology/European League against Rheumatism provisional definition of remission in rheumatoid arthritis for clinical trials. Ann Rheum Dis 70(3):404-413. https://doi. org/10.1136/ard.2011.149765

15. Osterberg L, Blaschke T (2005) Adherence to medication. N Engl J Med 353(5):487-497. https://doi.org/10.1056/NEJMra050100

16. National Institute for Health and Care Excellence (NICE) (2009) Medicines adherence: involving patients in decisions about prescribed medicines and supporting adherence. https://www. niceorguk/guidance/cg76/resources/medicines-adherenceinvolving-patients-in-decisions-about-prescribed-medicines-and- supporting-adherence-pdf-975631782085 Accessed 20 August 2019

17. Horne R, Chapman SC, Parham R, Freemantle N, Forbes A, Cooper V (2013) Understanding patients' adherence-related beliefs about medicines prescribed for long-term conditions: a metaanalytic review of the Necessity-Concerns Framework. PLoS One 8(12):e80633. https://doi.org/10.1371/journal.pone.0080633

18. Wei L, Champman S, Li X, Li X, Li S, Chen R, Bo N, Chater A, Horne R (2017) Beliefs about medicines and non-adherence in patients with stroke, diabetes mellitus and rheumatoid arthritis: a cross-sectional study in China. BMJ Open 7(10):e017293. https:// doi.org/10.1136/bmjopen-2017-017293

19. Zhang L, Lu GH, Ye S, Wu B, Shen Y, Li T (2017) Treatment adherence and disease burden of individuals with rheumatic diseases admitted as outpatients to a large rheumatology center in Shanghai, China. Patient Prefer Adherence 11:1591-1601. https:// doi.org/10.2147/PPA.S144624

20. Xia Y, Yin R, Fu T, Zhang L, Zhang Q, Guo G, Li L, Gu Z (2016) Treatment adherence to disease-modifying antirheumatic drugs in Chinese patients with rheumatoid arthritis. Patient Prefer Adherence 10:735-742. https://doi.org/10.2147/PPA.S98034

21. Kumar P, Banik S (2013) Pharmacotherapy options in rheumatoid arthritis. Clin Med Insights Arthritis Musculoskelet Disord 6:3543. https://doi.org/10.4137/CMAMD.S5558

22. Weinblatt ME (2013) Methotrexate in rheumatoid arthritis: a quarter century of development. Trans Am Clin Climatol Assoc 124: $16-25$

23. Fatimah N, Salim B, Nasim A, Hussain K, Gul H, Niazi S (2016) Frequency of methotrexate intolerance in rheumatoid arthritis patients using methotrexate intolerance severity score (MISS questionnaire). Clin Rheumatol 35(5):1341-1345. https://doi.org/10. 1007/s10067-016-3243-8

24. Singh JA, Saag KG, Bridges SL Jr, Akl EA, Bannuru RR, Sullivan MC, Vaysbrot E, McNaughton C, Osani M, Shmerling RH, Curtis JR, Furst DE, Parks D, Kavanaugh A, O'Dell J, King C, Leong A, Matteson EL, Schousboe JT, Drevlow B, Ginsberg S, Grober J, St Clair EW, Tindall E, Miller AS, McAlindon T (2016) 2015 American College of Rheumatology Guideline for the treatment of rheumatoid arthritis. Arthritis Rheum 68(1):1-26. https://doi. org/10.1002/art.39480

25. Wang G, Mu R, Xu H (2015) Management of rheumatoid arthritis in People's Republic of China - focus on tocilizumab and patient considerations. Int J Gen Med 8:187-194. https://doi.org/10.2147/ IJGM.S81633

26. Gibofsky A, Galloway J, Kekow J, Zerbini C, de la Vega M, Lee G, Lee EY, Codreanu C, Koehn C, Steinberg K, Bananis E, de Leon DP, Maniccia A, Dikranian A, RA NarRAtive global advisory panel (2018) Comparison of patient and physician perspectives in the management of rheumatoid arthritis: results from global physicianand patient-based surveys. Health Qual Life Outcomes 16(1):211. https://doi.org/10.1186/s12955-018-1035-3

27. Deng W, Hu J (2013) The effects of a pilot intervention for community-dwelling adults with rheumatoid arthritis in Wuhan, China. Front Public Health 1:43. https://doi.org/10.3389/fpubh. 2013.00043

28. Salliot C, van der Heijde D (2009) Long-term safety of methotrexate monotherapy in patients with rheumatoid arthritis: a systematic literature research. Ann Rheum Dis 68(7):1100-1104. https://doi. org/10.1136/ard.2008.093690

29. Nash P, Nicholls D (2013) Perceptions of methotrexate use in rheumatoid arthritis by rheumatologists and their patients: an Australian survey study. Int J Rheum Dis 16(6):652-661. https://doi.org/10. 1111/1756-185X.12183

30. Poor G, Strand V, Leflunomide Multinational Study Group (2004) Efficacy and safety of leflunomide $10 \mathrm{mg}$ versus $20 \mathrm{mg}$ once daily in patients with active rheumatoid arthritis: multinational double- 
blind, randomized trial. Rheumatology (Oxford) 43(6):744-749. https://doi.org/10.1093/rheumatology/keh168

31. Dougados M, Emery P, Lemmel EM, Zerbini CA, Brin S, van Riel $P$ (2005) When a DMARD fails, should patients switch to sulfasalazine or add sulfasalazine to continuing leflunomide? Ann Rheum Dis 64(1):44-51. https://doi.org/10.1136/ard.2003.016709

32. Salt E, Frazier SK (2011) Predictors of medication adherence in patients with rheumatoid arthritis. Drug Dev Res 72(8):756-763. https://doi.org/10.1002/ddr.20484

33. Cutolo M, Bolosiu H, Perdriset G, Group LS (2013) Efficacy and safety of leflunomide in DMARD-naive patients with early rheumatoid arthritis: comparison of a loading and a fixed-dose regimen. Rheumatology (Oxford) 52(6):1132-1140. https://doi.org/10.1093/ rheumatology/kes 321

34. Li R, Zhao JX, Su Y, He J, Chen LN, Gu F, Zhao C, Deng XR, Zhou W, Hao YJ, Xue Y, Liu HX, Zhao Y, Zou QH, Liu XY, Zhu P, Sun LY, Zhang ZL, Zou HJ, Li XF, Liu Y, Fang YF, Keystone E, McInnes IB, Li ZG (2016) High remission and low relapse with prolonged intensive DMARD therapy in rheumatoid arthritis (PRINT): a multicenter randomized clinical trial. Medicine
(Baltimore) 95(28):e3968. https://doi.org/10.1097/MD. 0000000000003968

35. Atsumi T, Yamamoto K, Takeuchi T, Yamanaka H, Ishiguro N, Tanaka Y, Eguchi K, Watanabe A, Origasa H, Yasuda S, Yamanishi Y, Kita Y, Matsubara T, Iwamoto M, Shoji T, Okada T, van der Heijde D, Miyasaka N, Koike T (2016) The first doubleblind, randomised, parallel-group certolizumab pegol study in methotrexate-naive early rheumatoid arthritis patients with poor prognostic factors, C-OPERA, shows inhibition of radiographic progression. Ann Rheum Dis 75(1):75-83. https://doi.org/10. 1136/annrheumdis-2015-207511

36. Xie HG, Kim RB, Wood AJ, Stein CM (2001) Molecular basis of ethnic differences in drug disposition and response. Annu Rev Pharmacol Toxicol 41:815-850. https://doi.org/10.1146/annurev. pharmtox.41.1.815

Publisher's note Springer Nature remains neutral with regard to jurisdictional claims in published maps and institutional affiliations. 